\title{
Diabetic Retinopathy and Visual Disability
}

\author{
T. R. Cullinan \\ Department of Environmental and Preventive Medicine, St Bartholomew's Hospital Medical College, London, UK
}

\begin{abstract}
Summary. Data from blind and partial sight registers and from special surveys have been analysed to derive estimates of the number of adults in England and Wales visually disabled by diabetic retinopathy. If visual disability is defined as 'less than 6/18 Snellen', approximately 30 per 100.000 adults living at home are disabled by diabetic retinopathy; if defined around traditional concepts of 'blindness' (approximately
\end{abstract}

$3 / 60$ vision or less) the estimated figure is about 20 per 100.000 total population. Annual additions to the blind register for diabetic retinopathy are about two per 100.000 total population. Weaknesses in data gathering are discussed.

Key words: Diabetic retinopathy, blindness, blind registration, visual disability.
It is often said that diabetic retinopathy is the commonest cause of blindness in the United Kingdom but the statement is true only in the sense that it applies to younger people who are registered as blind. It originates from analyses of blind registers $[1,2]$ which were initiated in the early 1920 's to bring social, economic and educational help to those severely disabled by poor sight. The main criterion for registration remains 'an inability to perform work for which eyesight is essential', which is usually taken to imply a distance visual acuity less than 3/60 (Snellen), although a few (about 5\%) are registered by reason of very diminished visual fields only. A second category of 'partial sight' was later added to accommodate those with manifest visual disability, yet not so severe as to qualify as 'blind'. Entrance to both registers is by way of a form completed by a consultant ophthalmologist and, although there has never been any obligation to do so, there have always been financial as well as educational benefits in becoming registered as blind. At present there are practically no benefits to becoming registered as "partially sighted', except among children needing special educational help.

It is obvious that registration, which has always brought more benefits in education and financial, rather than social, support, is more likely to be attractive to younger people and data derived from analyses of registers will under-represent the eye diseases that handicap in old age. This is the origin of any misconceptions there might be about the role that diabetic retinopathy plays in blinding diseases and it is useful to analyse both blind and partial sight registration as well as spe- cial surveys in order to place it in a more true perspective.

\section{Methods}

Sources have included the most recent analysis from the Department of Health and Social Security of registration data in England and Wales [2]; data from a national sample survey of 15.000 households in 1977, a complete survey of one city in 1974 [3], data from the Framingham eye study [4] and from blind registrations in the USA [5]. The national household study and the complete survey of a single city (Canterbury) were concerned with handicaps in general but so designed that a study of visually disabled people, and linkage with hospital records, proved possible. For the purposes of this paper, analyses have been directed solely towards visual disability ascribed to diabetic retinopathy (of all types) and not towards deriving estimates of the prevalence of diabetes or of retinopathy among diabetic patients.

\section{Results}

Diabetic retinopathy is undoubtedly the major single cause of registered 'blindness' before retirement age, accounting for $18-20 \%$ of all new additions to the blind register in each of the years 1969-1976 [2] and about 16\% to the partial sight register. However, there is ample evidence $(6-8)$ that registration among retired people is far from complete - an estimated $30-40 \%$ of elderly people eligible for registration as blind are not so registered and for partial sight the figure may be nearer $50 \%$.

The World Health Organisation (WHO) has attempted to overcome the restrictive nature of most of 


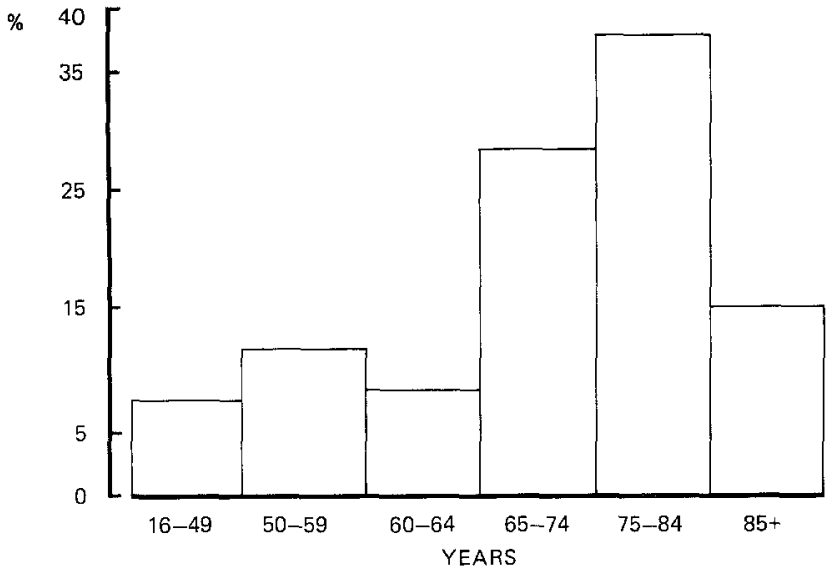

Fig. 1. Visually disabled adults - England and Wales 1977. Percentage age distribution

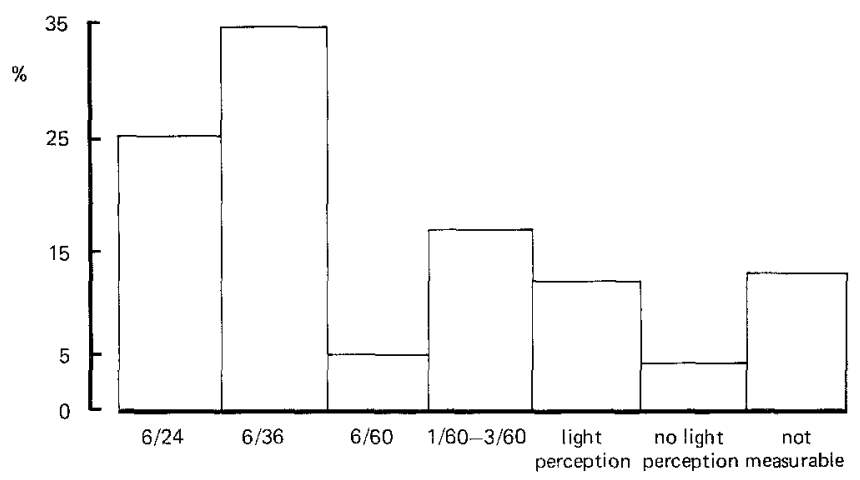

Fig. 2. Percentage distribution of visual acuity among visually disabled adults, England and Wales 1977

the 60 or so definitions of blindness in use round the world, by suggesting that data be collected on 'visual impairment' (equivalent to 'disability' in current English usage) defined as "less than $6 / 18$ vision in the better eye" [9]. This was the definition used in analysing the results from the two surveys, but included in it, of course, are those who have been traditionally regarded as 'blind' or 'partially sighted'. Approximately 520 adults (16 years and over) among every 100,000 adults living at home are visually disabled according to WHO definition; almost $80 \%$ of them are over retirement age and nearly $50 \%$ over the age of 75 years (Fig. 1).

Figure 2 shows the range of distance visual acuities among the visually disabled adults and demonstrates how restrictive a concept of 'blindness' or 'partial sight', based on traditional definition, is likely to be. Over a quarter $(26 \%)$ of visually disabled adults included in the two surveys had their disability ascribed to 'cataracts'; $18 \%$ to macular degeneration, $8 \%$ to 'glaucoma' and only $6 \%$ to diabetic retinopathy, reflecting the age specific prevalence of major disabling eye disease. These estimates, however, are based solely on the individual diagnoses made by many different ophthalmologists on that proportion of visually disabled people who had been referred for specialist care; both surveys suggested that
Table 1. The prevalence of visual loss attributed to diabetic retinopathy with respect to visual acuity

\begin{tabular}{|c|c|c|c|}
\hline $\begin{array}{l}\text { Level of } \\
\text { visual } \\
\text { acuity }\end{array}$ & $\begin{array}{l}\text { Prevalence } \\
\text { per } 100.000 \\
\text { population }\end{array}$ & $\begin{array}{l}\text { Annual } \\
\text { additions } \\
\text { to blind } \\
\text { register }\end{array}$ & $\begin{array}{l}\text { Additions } \\
\text { per } 100.000 \\
\text { population }\end{array}$ \\
\hline $\begin{array}{l}3 / 60-\text { no light } \\
\text { perception }\end{array}$ & $\begin{array}{l}18 \text { Males } \\
24 \text { Females } \\
(1970)\end{array}$ & $\begin{array}{l}324 \text { Males } \\
811 \text { Females } \\
(1970)\end{array}$ & $\begin{array}{l}\text { 1.4 Males } \\
2.7 \text { Females } \\
(1970)\end{array}$ \\
\hline $6 / 60-3 / 60$ & $\begin{array}{l}1.7 \text { Males } \\
3.4 \text { Females } \\
(1970)\end{array}$ & & \\
\hline $\begin{array}{l}6 / 24-\text { no light } \\
\text { perception }\end{array}$ & $\begin{array}{l}31 \text { Adults } \\
16 \text { years }+ \\
(1977)\end{array}$ & & \\
\hline $\begin{array}{l}6 / 9-\text { no light } \\
\text { perception }\end{array}$ & $\begin{array}{l}3,100 \text { aged } \\
52-85 \text { years } \\
(1975)\end{array}$ & & \\
\hline
\end{tabular}

this applied to hardly more than half of visually disabled adults. From those data a figure of some 12,750 adults in England and Wales, visually disabled by diabetic retinopathy, can be derived.

Such restricted estimates of prevalence have been much enhanced by the publication of the data from the Framingham eye study [7] which has produced estimates over a much wider range of acuity than that embraced by the WHO definition. Even in the Framingham study, sampling and follow-up difficulties must affect final estimates, but it is the only major population based study so far reported where care was taken to validate diagnostic accuracy and clear criteria for diagnosis established and maintained. At all levels of acuity prevalence of diabetic retinopathy (all stages) was $2.1 \%$ at ages 52-64 years, $2.9 \%$ at ages $65-74$ years and $7 \%$ at ages $75-85$ years. The sample was too small to deduce age specific rates at different acuity levels.

Estimates from registration data as well as special surveys can be combined to give an overall picture of the prevalence of visual disability attributed to diabetic retinopathy at different levels of visual acuity (Table 1 ). The first row of the table relates to the blind register of England and Wales and the second to the partial sight register - no detailed analyses have been published which include all age groups for any year since 1970 . Kahn and Hillier [5], reporting in 1974, found very similar rates of additions to the blind registers of the Model Reporting Areas in the United States in 1970 as in England and Wales. The disparities between males and females in Table 1 reflect much more demographic differences in age structure than differences in disease incidence or rate of registration.

\section{Discussion}

The presentation of such data as these may be useful in health and social service planning and in assessing the 
value of registration as a means of providing for those most in need but it contributes very little to a deeper understanding of the natural history of this disabling disease. This is partly because there is so much variance in the process of seeking and achieving registration and partly because the biological factors, including disease control, which determine the onset and progress of retinopathy among cohorts as well as individuals have not been well enough understood to become part of the process of regular data gathering. This is not to argue that trend analysis of registration data should cease for planning purposes it continues to be very useful, but it is to make a strong case for the inclusion in it of some of the factors such as length of disease which would give it more meaning. Lastly, there seems little point in further cross sectional studies, except for purely social reasons, unless they can include good data on disease process.

\section{References}

1. Sorsby A (1972) The incidence and causes of blindness in England and Wales 1963-1968. Reports on public health and medical subjects, Paper No 128 Her Majesty's Stationary Office, London

2. Department of Health and Social Security Blindness and partial sight in England 1969-1976. Reports on public health and medical subjects number 129, Paper No 129 Her Majesty's Stationary Office, London

3. Cullinan TR (1978) Epidemiology of visual disability. Trans Ophthal Soc UK 98: 267-269

4. Kahn HA, Leibowitz HM, Ganley JP, Kini MM, Colton T, Nickerson RS, Dawber TR (1977) The Framingham eye study, outline and major prevalence findings. Amer J Epidemiol 106: 17-32

5. Kahn HA, Hillier R (1974) Blindness caused by diabetic retinopathy. Amer J Ophthal 78: 58-67

6. Cullinan TR (1977) Visually disabled people in the community, Canterbury Report No 28. Health Services Research Unit, University of Kent

7. Graham PA, Wallace J, Welsby E, Grace HJ (1968) Evaluation of postal detection of registerable blindness. Bri J Prev Soc Med 22: 238-241

8. Brennan ME, Knox EG (1975) An investigation into the purposes, accuracy and effective use of the blind register in England. Bri J Prev Soc Med 27: 154-159

9. World Health Organisation (1978) The prevention of blindness. Technical Report Series No 518

Received: 20 May 1982

and in revised form: 29 July 1982

Dr. T. R. Cullinan

Department of Environmental and Preventive Medicine

St Leonard's Hospital

Nuttall Street

London N1 5LZ, UK 